\title{
Author Index Volume 23 (2003)
}

The issue number is given in front of the page numbers.

Bilder, G., Ingenta's economic and technical models for providing institutional OA archives

Bolman, P., Open Access: Marginal or core phenomenon? A commercial publisher's view

Charnay, D., The Centre for Direct Scientific Communication

den Hollander, F., see Voerman, G.

Dreier, T., The legal framework for access to STI

Dreier, T. and G. Nolte, Digital copyright and value added information services

Druiven, H., see Voerman, G.

Franklin, J., Open Access to Scientific and Technical Information: The state of the art Franklin, J., Summary of the discussions with commentary

Freedman, M.J., Continuity and change for U.S. libraries in the digital age: How U.S. public and academic libraries are confronting the challenge of the digital library

Goulding, A., see Han, L.

Gradmann, S., FIGARO and Open Access to electronic information objects

Grivell, L., E-BioSci: Semantic networks of biological information

Guedon, J.-C., The Budapest initiative for Open Access

Guillopé, L., Mathematics and databases: Open Access

Han, L. and A. Goulding, Information and reference services in the digital library

Handzel, R., see Lazinger, $\mathrm{S}$.

Harnad, S., The research-impact cycle

Keyzer, A., see Voerman, G.

Knopf, D. and C. Sorge, Model-oriented analysis of user - right holder relations and possible impacts of DRM

Lazinger, S. and R. Handzel, Offering distance education in Health Informatics: The state of the Web sites

Mainelli, M., Risk/reward in virtual financial communities

Mittler, E., Libraries and international infrastructure for Open Access services

Morris, S., Open Publishing: How publishers are reacting

Nolte, G., see Dreier, T.
$(2,3)$ 111-112

$(2,3) \quad 93-98$

$(2,3) 133-137$

(1) $1-7$

$(2,3)$ 119-120

(4) $241-250$

(1) $1-7$

$(2,3) \quad 67-86$

$(2,3) 191-198$

(4) $211-226$

(4) $251-262$

$(2,3) 175-177$

$(2,3)$ 179-182

$(2,3) 171-173$

$(2,3) 127-131$

(4) $251-262$

(1) $19-34$

$(2,3)$ 139-142

(1) $1-7$

(4) 235-239

(1) $19-34$

(1) $9-17$

$(2,3)$ 117-118

$(2,3) \quad 99-101$

(4) $241-250$ 
Powell, A., A brief overview of the OAI Protocol and it's potential impact

$(2,3) 103-104$

Prosser, D., Institutional repositories and Open Access: The future of scholarly communication

$(2,3) 167-170$

Siegel, E.R. and F.B. Wood, The National Library of Medicine's strategy for assessing the impacts of health information Web Sites

(4) $227-234$

(4) 235-239

Tedd, L.A., Library co-operation and ICT in the UK: An overview

(4) $199-210$

Tröger, B., The information alliance for education, social sciences and psychology - A onestop-shop for the benefit of users

(4) $263-267$

Uhlir, P.F., Re-intermediation in the Republic of Science: Moving from intellectual property to intellectual commons

$(2,3) \quad 63-66$

Velterop, J., Open Access Publishing

Voerman, G., A. Keyzer, F. den Hollander and H. Druiven, Archiving the Web: Political Party Web sites in the Netherlands

$(2,3) 113-115$

Wood, F.B., see Siegel, E.R.

(1) $1-7$

(4) 227-234 